\title{
System approach to organization of lean production
}

\author{
Saida Kuizheva ${ }^{1}$, Lyudmila Zadorozhnaya ${ }^{2}$, Sergey Chefranov $^{3}$, Zarina Gasheva ${ }^{4}$ \\ ${ }^{1}$ Associate Professor, Ph. D., Federal State Budgetary Educational Institution of Higher Education \\ «Maikop State Technological University», Maikop; \\ ${ }^{2}$ Professor, Ph. D., Federal State Budgetary Educational Institution of Higher Education «Maikop State \\ Technological University», Maikop; \\ ${ }^{3}$ Professor, Ph. D., Federal State Budgetary Educational Institution of Higher Education «Maikop State \\ Technological University», Maikop; \\ ${ }^{4}$ Graduate student, Federal State Budgetary Educational Institution of Higher Education «Maikop State \\ Technological University», Maikop.
}

\begin{abstract}
The complex of organizational problems of the process of distribution of lean production is Considered. The analysis of directions, specific measures and tools of formalization of the process of distribution of lean production is carried out. Features of procedures of the analysis of the current state and synthesis of specialized systems of management of process of distribution of lean production in the environment of economic subjects are defined, namely: development and introduction of the self-regulating organizations, technocenoses, multiagent systems, technologies of OLAPcube, Big Data.

Keywords: lean production, cyber-physical systems, multi-agent systems, self-regulating organizations, technocenoses, OLAP-cube technologies, Big Data.
\end{abstract}

\section{Introduction}

The concept of "Lean Production" (LP) is based on the desire of business entities (BE) to constantly eliminate all types of losses that occur during the management of business and production [1]. The process of introducing lean production into the activities of BE can be represented at the macro (state), meso (region, industry) and micro level (specific enterprises and institutions). The concept implies the possibility of a significant improvement in business processes, both on the basis of involving each employee of this particular BE in the organization, production and business process of improvement, but even more of all contractors of his activity.

The most important objective of the concept is to assess the value of the manufactured product for the end user at each stage of its creation. In accordance with the concept of LP, all activities of $\mathrm{BE}$ are divided into operations and processes, which allows you to take advantage of the process organization of labor [2], adding or not adding values to the consumer. 
Traditionally distinguish losses arising from: overproduction; long waiting times; irrational transportation and movements; excessive processing steps; excess stocks; defective product release; unrealized creative potential of employees, etc.

LP ideas are currently applied in various fields of activity: the education system, services, public utilities, healthcare, the armed forces, government, etc. A huge number of participants are involved in this process, and, along with the issues of ensuring the LP process itself, there are problems of its systemic organization, rational communication of participants (exchange of experience, joint problem solving). Traditional methods of accounting for BE activity, based on rigid, deterministic algorithms, hinder the development and implementation of the BE concept.

Consider the most important problematic issues that determine the objectives of this study:

1. Participants in the process cannot be considered as elements of one system [3] (different degrees of activity, presence of their own interests and opportunities, different effects from implementation). That is, these are not system elements, but network agents. This fact forms a special style and format of relations. Mostly market. Indeed, the main goal of LP is to achieve economic and / or social effect, and the first goal of the study is the development of network forms and methods of interaction between participants.

2. An avalanche-like increase in the dimensional characteristics of information flows in the network with an increase in the number of agents. Here is just one example that confirms this property of a network of BE that jointly profess the concept of LP. Table 1 shows the dependence of the number of bonds $\mathrm{S}$ on the number $\mathrm{n}$ of participants in a LP network. That is, it is necessary to provide for the possibility of processing large volumes of heterogeneous information in real time.

Table 1. The growth of ties in the LP network

\begin{tabular}{|c|c|c|c|c|c|c|c|c|c|}
\hline$n$ & 2 & 3 & 4 & $\ldots$ & 10 & 11 & 12 & $\ldots$ & $n$ \\
\hline$S$ & 1 & 3 & 6 & $\ldots$ & 45 & 55 & 66 & $\ldots$ & $\left(n^{2}-n\right) / 2$ \\
\hline
\end{tabular}

It should be borne in mind that the amount of information processed depends not only on the number of participants, but also on other factors: the degree of development of the LP concept for the BE (internal document flow), the degree of automation of document flow, digitalization of production, the breadth of the spectrum of tasks to be solved, etc.

3. High uncertainty and heterogeneity of the data used. Really:

- The difference in the areas of activity of BE leads to an ambiguous interpretation of the principles of LP, to a contradictory interpretation of the results of activities.

- Many factors are evaluated at a qualitative level with the involvement of experts. That is, there is a high degree of subjectivity of the assessment, and data objectification technologies are necessary.

These problems require the development of intelligent data processing systems - the third goal of the study.

\section{Methods and materials}

To solve the problems formulated in this study, it is proposed to identify areas, specific measures and tools that are promising from the point of view of practical application:

1. For the effective dissemination of lean production, it is proposed in environment BE, interacting under the LP program, to create self-organizing schemes. A concrete example of the form of such a self-organizing system can serve as self-regulatory organizations (SROs) [4]. Regulation on SRO approved by the State Duma of the Russian Federation. The basic principles of SROs: accept only competitive participants (this requirement stimulates the development of $\mathrm{BE}$ ), collective responsibility for labor results (reduces risks for the top 
management level), rational distribution of tasks within the SROs (ensures the effectiveness of each BE). SROs are tuned to the BE micro level and interact with the meso and macro levels.

The second example of a self-organizing interaction is technocenosis [5]. It serves as a functioning model for the BE meso- and macrolevels. Cenosis - a set of interconnected objects of different nature, ensuring their joint survival, resisting external and internal influences. Technocenosis BE LP - a new quality of production that applies to the industry, region, state as a whole. The technocenosis model, based on empirical data, allows you to evaluate: the completeness of cenosis (by the accuracy of the approximation of the curve describing the cenosis), the degree of maturity of LP organization (by the parameters of the cenosis model). Models of technocenosis BE LP, built at different points in time, allow us to assess the dynamics of its development (improvement or degradation).

2. Coordination of interests of network participants is carried out using methods of the theory of active systems (TAS) [6]. TAS covers the solution of a wide range of organizational management issues. In the first place should indicate the formalization of the procedures for various competitions. Objectification of making an informed decision takes place through mathematical modeling of the competitive process (the engagement of experts and managers is excluded; their professionalism is stimulated). In addition, it also ensures coordination of the interests of both BE of one and BE of different levels of management, stimulation of work (of individual employees and teams).

3. The introduction of intelligent methods for obtaining, storing and processing information. For instance:

- Using OLAP-cube technology, you can quickly (automatically) get information on any system of issues related to BE activities in the field of LP. The OLAP cube automatically organizes the information received on various dimensions of the information cube (set by experts), supplements, stores in a convenient format for use, and provides regulated access to users (BE, managers at various levels).

- Using Big Data (Big Data) technology, you can operate with significant arrays of heterogeneous data. In addition to the obvious expansion of the range of tasks (by obtaining additional information), Big Data allows you to organize contextual decision making.

4. The handling of big data, in turn, sets the task of accurate and stable data transmission, protecting it from distortion (accidental and intentional). The solution to this problem is seen in the application of blockchain technologies [7].

5. The introduction of multi-agent technologies (MAT), which, using the intelligence of the developers (broadcasting it to the machine), additionally form the intelligence of the community, as a category independent of the intelligence of the constituent agents of this community [8].

The following analogy is often given: each individual ant or bee, obviously, does not possess intelligence. At the same time, the colony of ants (swarm of bees) as a whole exhibits appropriate behavior, which can already be interpreted as intellectual. These phenomena (depending on the fields of application, the positions of scientific schools studying this phenomenon) received different names: "emergent intelligence", "intellectual resonance", "swarm intelligence", etc. This intelligence is the result of self-organization in the activities of agents (we have BE professing the ideology of LP). Thus, it is hereby proposed to use this effect in the organization of LP.

MAT exhibit intellectual behavior due to the presence of the following properties:

- they have the ability to identify the external and internal environment, are able to respond to changes occurring in them. This property is called reactivity;

- each agent takes the initiative, implements controlled behavior, performing actions aimed at achieving his goals. This property is called proactivity; 
- the agent's ability to act in concert with other entities of the external and internal environment (other agents, technical and technological systems, people, etc.) is called sociality.

Agents perform actions aimed primarily at preserving their parameters, and not the parameters of the system as a whole (which is typical for system interactions). Preservation of system properties in the aggregate of agents occurs indirectly, insofar as this corresponds to their interests.

The formalized representation of the MAT.

The theory of multiagent systems is already a fairly developed field. Consider one of the possible ideas about the structure and functions of the agent (its formalized model).

Above, we have already defined the properties of the agent:

- he has his own goals of functioning and understanding of the outside world;

- identifies its current state and the state of the dive environment;

- has a logic that determines its behavior;

- can communicate with other agents and with the environment in the process.

The parts of the agent responsible for collecting information are called sensors, and for the impact on the environment, they are called effectors.

Based on this description, you can draw up a diagram representing the approximate internal structure of the agent, its position in the environment, as well as interaction with other agents (Figure 1).

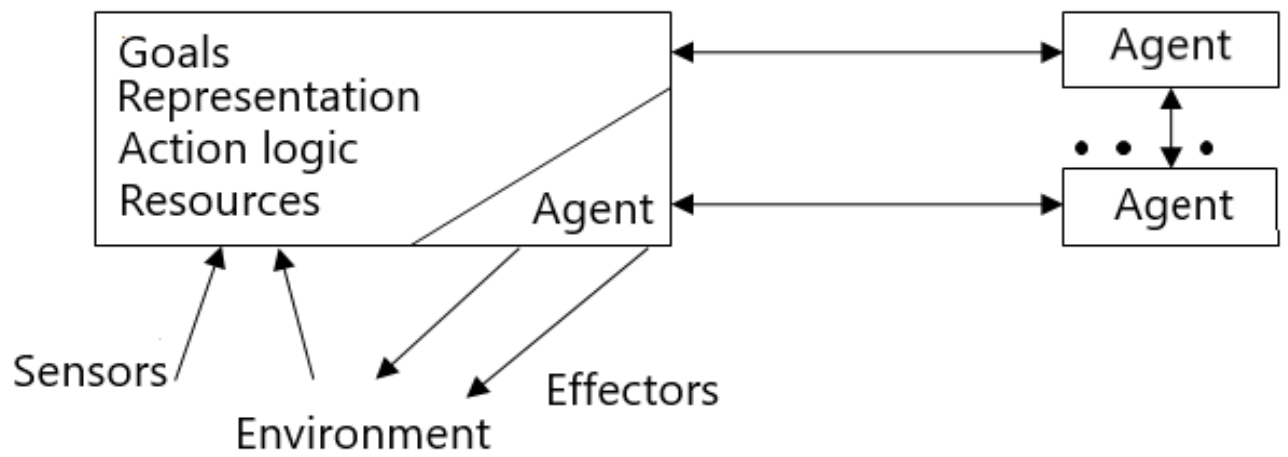

Fig. 1. The device of the agent and its position in the dive environment, compiled by the authors.

A large rectangle reveals the internal structure of a single agent. It is characterized by goals, resources, the logic of internal organization. Agents interact with the environment and with each other.

5. All of the above aspects of improving the distribution process of LP form a qualitatively new idea, called the "cyberphysical system" (CPS), using the Internet of people, things, services, multi-agent technologies [7, 8].

CPS is a concept of information and technological integration of computing resources into entities of any kind (physical - through the Internet of things [8]), biological (people and groups of people), man-made objects (organizational, automated control systems). In CPS, the computing component is distributed throughout the synthesized system. It provides the operation of digital platforms that solve specific production, socially significant problems [8, 9].

In CPS, measuring devices, executive equipment, information systems, people (operators and goal managers, experts) are united by a single technology throughout the entire value chain that goes beyond the boundaries of one enterprise or business. These systems interact with each other using standard Internet protocols for forecasting, self-tuning and adaptation to changes. 


\section{Results}

LP is based on production problems, and the complexity of the tasks to be solved requires:

- Implementation of a systematic approach to the study and synthesis of lean manufacturing.

- Application of new organizational forms of interaction (self-regulatory organizations).

- Application of modern approaches and methods, namely, methods of the digital economy (CPS, MAT, blockchain) and artificial intelligence methods (OLAP cubes, Big Data).

- Development and adaptation of new mathematical tools (theory of technocenoses, theory of active systems).

\section{Conclusions}

In this study:

1. Proposed a network organization of BE, professing the ideas of LP, organized on the principles of CPS.

2. The meaning of multi-agent organization for improving and developing LP is revealed.

3. A complex of mathematical tools is indicated that is promising for the study, analysis and management of LP (TAS, technocenosis models).

The authors believe that this will allow a more complete study of LP in Russia. In this regard, it is important to take into account the opinion of foreign researchers and experts. So, Bob Vavra believes that the companies that implemented Lean (Toyota, GE, FedEx, Dell) have become one of the most profitable and respected in the world. In his opinion, Lean's problem is "not in saving size or scale, but in Lean's commitment" [10]. No less important is the opinion of Daniel T Jones that "Lean is a path or path of individual and organizational learning that leads to more complex and meaningful work for all participants" [11].

\section{List of abbreviations}

Big Data - Big Data

LP - Lean Production,

CPS - cyber-physical system,

MAT - multiagent technologies,

SRO - self-regulatory organizations,

TAS - theories of active systems,

BE - business entity

\section{References}

1. Woomek James P., Jones Daniel T. Lean Manufacturing. How to get rid of losses and prosper your company. - M.,: "Alpina Publisher", 2011. At the beginning of the $21 \mathrm{st}$ century, other books on this subject were also published in Russia, for example, Voumek James P., Jones Daniel T. Lean provision. How to build effective and mutually beneficial relationships between suppliers and consumers. - M., Alpina Business Books, 2006; Vader Michael Lean Tools. - M., Alpina Business Books, 2005; George Michael Lean Manufacturing + Six Sigma. Combining the quality of six sigma with the speed of lean manufacturing. - M., Alpina Business Books, 2005; Muskell Brian and Buggali Bruce The practice of lean accounting. Management and financial accounting and a system of responsibility in lean enterprises. - M., ICSI. 2100; 
2. For more details, see Repin VV, Eliferov V.G. The process approach to management. Modeling business processes. - 6th ed. - M.: RIA "Standards and Quality", 2008.

3. Very few studies have been devoted to questions of a systematic approach to the problems of lean manufacturing in Russia: we mention the works of II. Antonova Lean production: system approach to its implementation at the enterprises of the republic of Tatarstan Kazan, Poznanie Publishing House (Kazan), 2013, P. 176; Galeeva R.R. System approach to the organization of lean production // New science: problems and prospects, No. 6-1 (85), 2016, SS. 46-50; Strekalova G.R. System approach to simulation of lean production at industrial enterprises // SCIENTIFIC NOTES ISGZ, Volume: 15, No. 1, 2017, PP. 511 517

4. Belotserkovsky, A. Self-regulatory organizations in higher vocational education: "weather forecast" / A. Belotserkovsky // Higher education in Russia. - 2008. - No. 12.

5. Kudrin B.I. Classics of technical cenoses. General and applied cenology. Vol. 31. "Cenological studies" / B.I. Kudrin. - Tomsk: TSU - Center for System Research, 2006.

6. Novikov, D.A. Theory of management of organizational systems / D.A. Novikov. - M .: MPSI, 2005.

7. Tarasov V.B. From multi-agent systems to intelligent organizations: philosophy, psychology, computer science. - M.: Editorial URSS, 2002 .- 352 p.

8. Rosenberg I.N., Shabelnikov A.N., Lyabakh N.N. Sorting process control systems within the framework of the ideology of the Digital Railway: Monograph. - Moscow: VINITI RAS, 2019.

9. R. G. Sanfelice. Analysis and Design of Cyber-Physical Systems. A Hybrid Control Systems Approach // Cyber-Physical Systems: From Theory to Practice / D. Rawat, J. Rodrigues, I. Stojmenovic. - CRC Press, 2016.

10. Bob Vavra. Which way do you LEAN?//BY BOB VAVRA, EDITOR MARCH 15, 2008/ https://www.plantengineering.com/articles/which-way-do-you-lean/

11. Daniel T Jones What Lean Really is//posted on September 11, 2014/http:/www.leanuk.org/article-pages/articles/2014/september/11/what-lean-reallyis.aspx. 